\title{
Diagnosis and Management of Uric Acid Nephrolithiasis
}

\author{
N IQBAL M.N CHUGHTAI \\ Department of Urology. Allama Iqbal Medical College/Jinnah Hospital, Lahore \\ Correspondence to Dr. Naveed Iqbal, Senior Registrar Urology
}

\begin{abstract}
Objective: - The aim is to provide an account of the diagnosis \& management of uric acid stones. Material \& methods: A search was made on the topic of uric acid stones with regard to the diagnosis \& management of uric acid stones. Results: The incidence of uric acid stones varies between countries and account for $5 \%$ to $40 \%$ of all urinary calculi. Uric acid stone cannot be seen on $\mathrm{x}$-ray. Intra venous uroghraphy, CT scan or sonoghraphy is required for their diagnosis. This is the only stone that can be reliably dissolved by urinary alkalization with alkali (Bicarbonates, citrate). This medical treatment is highly effective resulting in dissolution of existing stones \& prevention of stones. Extracorporeal shock wave lithotripsy and percutaneous nephrolithotripsy can be used successfully for uric acid stones. Open surgery is still performed especially for large complicated staghorn stones. Conclusion: Medical management with urinary alkalization for uric acid stone dissolution and prevention of recurrence is effective.
\end{abstract}

Key Words: - Uric acid stones, Diagnosis and Management.

The formation of stones in the urinary tract is an ancient disease in the history of humanity ${ }^{1,2,3}$. It achieved importance not only by virtue of its antiquity but also due to its frequency throughout the world ${ }^{4}$. The incidence of stone has been estimated to be as high as $12 \%{ }^{5}$. Pakistan falls in high stone belt area. Urolithiasis is a common ailment in our country. In 1930 Mcc Carrison cited by Khan ${ }^{6}$ published his data on the incidence of stone disease in India. He showed that high incidence was in Dera Ghazi Khan followed by Hyderabads \& Sukhur. It is believed that highest incidence is in lower Punjab and Northern $\operatorname{Sindh}^{7}$. It is well established that people living in a hot climate have a higher incidence of urolithiasis ${ }^{8,9}$. It has been partly attributed to low urinary out put (dehydration), hormonal effects (Vitamin D) induce by ultraviolet light and super saturation of calcium salts $s^{10,11,12,13}$. The incidence of calculi in the urinary tract is quite variable in different regions. This result from geographical difference, ethnic variation, the standard of living, diet and employment. There are more cases from the urban as compared to the rural population. Upper urinary tract stone disease in Pakistan occurs at all ages with the peak incidence among 16-20 years and has a high rate of recurrence ${ }^{14}$.

Kidney stones are formed from crystals of one or other molecules. It may be formed of combinations of elements or rarely protein matrix ${ }^{15}$. Matrix component of urinary stones varies ranging from 2 to $10 \%$ by weight ${ }^{16}$. ${ }^{17}$ It may serve as a nidus for crystal aggregation and co precipitate in the process of stone formation ${ }^{18}$.

Uric acid is a common component of urinary stones. It may contribute to calcium oxalate stone formation. ${ }^{19}$ Gout disease \& its association with uric acid has long been recognized. 10 to $20 \%$ of the patients with gout are associated with uric acid stones ${ }^{29}$. Uric acid stones prevalence in patients with ileostomy vary from 50 to $70 \%{ }^{21}{ }^{22}$ These patients tend to pass low volume acidic urine due to losses of fluid and bicarbonates from the gastrointestinal tract. ${ }^{23,}{ }^{24}$ Uric acid over production in patients with myeloproliferative disorder, leukemia and hemolytic anemia may be associated with uric acid stones $^{25}$. Uric acid is an end product of purine metabolism. It is formed in the body from three sources:1) de novo synthesis, 2) diet and 3) tissue metabolism ${ }^{26,27}$.

Uric acid stones comprise 5 to $8 \%$ of all cases of stone disease in western countries ${ }^{28}$. The frequency of uric acid stones has worldwide variation. Generally, these stones occur in an older population compared with other stone types ${ }^{29}$. Urate stones have been reported in Pakistan and Iran. The majority of these stones are ammonium and urate. ${ }^{30}$ Uric acid stones are the most common cause of radiolucent stones of urinary $\operatorname{tract}^{31}$.

Three factors are known for uric acid stone formation: acidic urine, hyperuricuria,

and decreased urine volume $e^{32,33,34}$. The dissociation constant $\mathrm{pKa}$ of uric acid is $5.7^{35,36}$. Thus the solubility of uric acid is $\mathrm{pH}$ dependent. Uric acid crystals are relatively insoluble and can precipitate when urinary $\mathrm{pH}$ is low. ${ }^{37}$ All conditions that lead to hyperuricuia, dehydration or low urinary volume will increase uric acid supersaturation and risk of stone formation ${ }^{38,39}$.

\section{DIAGNOSIS}

Symptoms and signs at presentation Pain is the main symptom at presentation. Other manifestation of uric acid stone presentation may be hematuria, urinary tract infection (fever, nausea, vomiting) or renal failure. ${ }^{40}$ Uric acid stone may be discovered incidentally when patient is evaluated for disease other than urinary tract disease. Detail medical history is important to identify factors associated with hyperuricosuria: Familial Gout, uricosuric medicine, myeloproliferative disorders, ${ }^{38}$ Lesch Nyhan disease, Polycythemia, Hemolysis, Purine disorder, inflammatory bowel disease, dehydration, renal insufficiency or dietary induced hyperuricuria ${ }^{41,42}$

\section{Physical findings}

1. No physical finding is sensitive or specific for uric acid stone.

2. Patients with malignancy may have finding such as lymphadenopathy, hepatosplenomegally. 
3. Tophi may be present ${ }^{40}$.

\section{Laboratory Studies}

Stone analysis should be obtained. Basic laboratory tests include urinalysis, serum electrolytes, uric acid, creatinine blood urea nitrogen \& calcium. A consistently low urinary $\mathrm{pH}<5.5$ indicate further evaluation for uric acid stone. An initial 24-hours urine sample collection for analysis of hypercalciuria, hyperuricuria, ' hyperoxaluria, hypocitraturia, sodium and volume. A spot urine $\mathrm{pH}$ should be obtained ${ }^{38,41,42}$.

\section{Imaging studies:}

Uric Acid stone cannot be seen on x-ray. Both xanthine and 2,8-dihydroxyadenine are also radiolucent. ${ }^{43}$ Patient may present with a radiopaque stone if uric acid is mixed with calcium oxalate or calcium phosphate. ${ }^{44}$ Renal ultrasonography is effective in identifying the stones. It is painless, noninvasive \& patient is not exposed to radiation or contrast. It often is not a good test when stone is in the ureter. However in this case ureter is abnormally dilated.

\section{Computerized Tomography (CT scan)}

Non contrast computed tomography scanning enhanced is the most sensitive to detect urinary stones. ${ }^{45}$ It is more sensitive than ultrasound or $\mathrm{x}$-ray. It is performed by placing the patient in $\mathrm{x}$-ray tube. It creates several imaging of kidneys, ureter and bladder. It can detect both calcium and non-calcium stones. In a recent study the mean density of 17 uric acid stones (344+152 hounsfield units) was significantly different compared with 82 calcium oxalate stones $\left(652+490\right.$ hounsfield unit). ${ }^{46}$ Uric acid stones appear as a dense image on CT. It can better differentiate uric acid stone from other radiolucent lesion like transitional c ell c arcinoma, fungal bezoars. Since it scans many organs, it can sometimes detect non-stone causes of pain. Non contrast enhanced CT scan fails to detect indinavir radiolucent stones. ${ }^{47}$

\section{Intravenous Urography (I.V.U)}

It is useful to detect stones in the ureter. A stone appears as a filling defect on imaging.

Retrograde Pyelography

Retrograde pyelography may be necessary to localize stone. It also defines upper urinary tract anatomy.

\section{Treatment}

a) Medical treatment

The goal of medical treatment is to dissolve formed stones $\&$ prevent new stone formation. ${ }^{42}$ Medical therapy can be divided into three parts:

1. Urinary alkalization

2. Decrease urinary uric acid

3. Urinary volume should be $>1.5 \mathrm{~L}$ in 24 hours.

\section{Urinary alkalization}

The goal of urinary alkalization is to achieve a $\mathrm{pH}$ of 6 to $6.5{ }^{48 .}{ }^{49}$ Oral alkalinizing a gents include sodium or potassium bicarbonate and potassium citrate.$^{50}$ Citrate is metabolized to bicarbonate. Polycitra contain potassium and sodium citrate and citric acid. Bicitra contains only sodium citrate and citric acid.
Potassium citrate is used in dose of $60 \mathrm{meq}$ in 3 or 4 divided doses. It is available in liquid, tablets and crystal form. It must be mixed with fluid. It should be avoided in-patients susceptible to hyperkalemia. The sodium alkali are also used to alkalize urine. ${ }^{51}$ Extra care should be taken in prescribing sodium alkali inpatients susceptible to fluid overload ${ }^{.38}$ The sodium load may initiate calcium oxalate stone formation by increasing urinary excretion of sodium \& calcium $^{52}$. A combination of sodium bicarbonate \& acetazolamide proved to be successful in minimizing side effects. ${ }^{53}$

Orange juice and commercial baking soda can be used. A dose of 1 to 2 tsp. thrice a day is generally" effective $^{34}$.

Intravenous alkalization with one-sixth molar sodium lactate is also effective. Sodium lactate in the solution is metabolized into b icarbonate in one to two hours. Intrarenal alkalization through a percutaneous nephrostomy tube was a common practice in the past. Sodium bicarbonate 2-4 ampoules in one liter of normal saline ( $\mathrm{pH} 7.0$ to 9.0 ) are used for irrigation. Other agents include tromethamine- $\mathrm{E}$ and tromethamine $(\mathrm{pH}$ 8.0- 10.5). ${ }^{55}$ These procedures require prolong hospitalization and endoscopic manipulation. ${ }^{56}$

Higher $\mathrm{pH}$ values may result in calcium phosphate stones formation and should be avoided. ${ }^{38}$ Increase fluid intake is recommended in chronically dehydrated patients. ${ }^{39}$

\section{Decrease urinary uric acid}

A diet rich in purines (red meat, fish \& poultry) ${ }^{57}$ is most common cause of hyperuricosuria. To lower purine intake from food one should avoid liver, kidney, beans, meat, yeast extract and red wine. Also avoid large meal \& plan day on three meals i.e Break fast, lunch, dinner.

Uric acid- lowering agents- used to decrease the production of uric acid. Allopurinol is a xanthineoxidase inhibitor. It decreases the production of uric acid. \& reduce both the serum \& urinary levels of uric acid. $^{58}$ Adult dose is $100-300 \mathrm{mg} /$ day. Allopurinol is generally well tolerated, best when taken after meals. Documented hypersensitivity is absolute contraindication. Minor side effects include skin rashes, gastrointestinal irritation, and altered liver function. Safety for use in pregnancy has not been established. ${ }^{41}$

b) Surgical treatment

Not all urinary tract uric acid stones pass spontaneously. They may not respond to systemic alkalization. Stones not responding to systemic alkalization are best managed by extra-corporeal shock wave lithotripsy (ESWL $)^{59}$ This type of procedure depends on stone size. All lithotripsy modalities are effective in stone fragmentation. Despite the risk of cyanide production from Holmium:YAG lithotripsy of uric acid stone, no evidence of cyanide toxicity was observed. ${ }^{60}$ Fragmentation of uric 
acid stones after ESWL improve oral chemolysis by increasing the s tone surface. ${ }^{50} \mathrm{~F}$ or the 1 arger $\mathrm{s}$ tones, both Per-Cutaneous Nephrolithotripsy (PCNL) and ESWL is successful. Open surgery is still reserved for large complicated staghorn calculus. ${ }^{61.62}$

\section{Conclusion}

Medical management with urinary alkalization and simple diet restriction is effective for stone dissolution and prevention. Small stones should be treated with ESWL. Large stones require ESWL, PCNL and open surgery in alone or in combination.

\section{References}

1. Kim SC, Moon YT, and KIM KD: E.S.W.L monotherapy. Experience with piezoelectric second-generation lithotriptor in 642 patients. J.Urol 1989:142674-78.

2. Beck. CW, Mulvaney WP. Apataic urinary calculi from early american indian. JAMA 1966; 195,168.

3. Drach GW, Dretler S, Fair W. Extracorporeal shock wave lithotripsy. J.Urol 1986; 135:1127-33.

4. Joly JS. Stone and calculus disease of the urinary organ. London, William Weiman. 1929;pp 1-7.

5. Frank P, Begun, MD, W. Dennis Foley. Patient evaluation laboratory and imaging study. Urologic clinic of North America 1997; 24. 97-100.

6. Khan FA, A history of calculus disease of the urinary tract. J Pak Med. Ass 1973; 1:19-24.

7. Khan FA. Basic data on urinary tract stones in Pakistan. Bulletin 1979; 12; 79-83.

8. Parry,e.S and Lister,I.S.: Sunlight and hypercalciuria. Lancet, $1975 ; 1: 1063$.

9. Pierce, L. W . and B loom, B.: O bservations on u rolithiasis among American troops in a desert area.J.Urol. 1978; 50; 499.

10. Robertson,W. G., Peacock,M., Heyburnu, P. J., Marshall ,D. $\mathrm{H}$ and Clark,P. B.: Risk factors in calcium stone disease of the urinary tract. Brit.J. Urol., 1978; 50: 499.

11. Varghese, M., Rodman, J. S., et al.; The effect of ultraviolet $B$ radiation treatment on calcium excretion and vitamin $D$ metabolites in kidney stone formers. Clin. Nephrol 1989; 31 : 225.

12. Frank, M. and De Vries, A.: Prevention of urolithiasis. Education to adequate fluid intake in a new town situated in the Juedean Desert Mountains. Arch.Environ.Health, 1966; 13:625.

13. Better, O.S., Melamud, A., Shabtai, M., Berenheim, J. and Chaimowitz, C.: studies on the pathogenesis of increased incidence of nephrolithiasis in lifeguard in Israel. Clin. Res. 1978; 26:126A

14. Khan S, Tufail: M, Husain Z, and Zaib J. Experience with the "Lithostar Plus" in the management of renal and ureteric stones. Pak. J surg.1993; 9: 56-61.

15. Morse RM, Resnick MI: Urinary stone matrix. J Urol 1988; 139:602.

16. Boyce, W. H, Garvey FK. The amount and nature of the organic matrix in urinary calculi, a review. J. Urol. 1956; 76: 213.

17. 17.Boyce, W. H. and king jr., J.S.; Crystal matrix interrelations in calculi. .J. Urol., 81:351,1959.
18. Vermulen, O.W. and Lyon, E. S.: Mechanism of genesis and growth of calculi. Am. J. Med., 45: 684, 1968.

19. Iwata $\mathrm{H}$ : The organic matrix of urinary uric acid crystals. J.urol.1988; 139:607.

20. Yu, T. and Gutman, A.B.:Uric acid nephrolithiasis in gout. Predisposing factors. Ann. Intern. Med; 1967; 67:1133.

21. Deren, J. J., Porush, J.G., Levitt, M.F. and Khilnani, M. T.: Nephrolithiasis as a complication of ulcerative colitis and regional enteritis. Ann. Intern. Med., 56: 843, 1962.

22. Bennett, R.C. and Hughes, E. S: Urinary calculi and ulcerative colitis. Brit. Med.J., 1972,2: 494.

23. Robin S. McLEOD and David N. Churchil. Urolithiasis complicating inflammatory bowel disease. J. Urol., 1992, $148,974-978$

24. Clarke, A. M. and Mc Kenzie, R. G.: Ileostomy and the risk of urinary uric acid stones. Lancet, 1969, 2, 395.

25. Yu, T. F., Weeinreb, N., Wittman, R. and Wasserman, L. R.: Secondry goutassociated with chrinic myeloproliferative disorder. Sem. Arthr. Rheum., 1976, 5:247.

26. Seegmiller, J. E., Laster, L. and howell, R.R.: Biochemistry of uric acid and its relation to gout. New Engl. J. Med., 1963, 268: 712 and 746.

27. Pak, C Y. C., barilla, d. E., holt, K., Brinkley L... Effect of oral purine load and allopurinol on the crystallization of calcium salts in urine of patients with hyperuricosuric calcium urolithiasis. Amer. J. Med., 1978, 65; 593.

28. Richard J. Riese and Khashayar Sakhaee.: Uric acid nephrolithiasis: Pathogenesis and treatment. J. Urol., 1992, 148: 765-771.

29. Gentle D.L, Stoller M.L, Bruce J.E, Lesile S.W. Geriatric urolithiasis. J. Urol 1997; 158: 2221.

30. Minon Cifuentes J, Pourmand, G: Mineral composition of 103 stones from Iran. Br J Urol. 1983; 55:465.

31. Richard Neiberger, Director of Pediatric renal stone disease clinic, University of Florida and Shands Hospital. Uric acid stones, 2003.

32. Tetsuo Murayama, Hirokazu Taguchi. The role of the diurnal variation of urinary $\mathrm{pH}$ in determining stone compositions. 1993. 150, 1437-1439.

33. Broadus A. E.. Metabolic basis of renal-stone disease. New Engl. J. Med., 1979, 300; 839.

34. Clarke AAM,. Chirnside A, Hill G L. Chronic dehydration and sodium depletion in patients with established ileostomies. Lancet, 1967,2: 740.

35. Finlayson B, Smith A. Stability of first dissociable proton of uric acid. J. Chem. Eng. Data, 1974, 19:94.

36. Pak CYC, Waters O, Arnold Holt K. Mechanism for calcium urolithiasis among patients with hyperuricosuria: super saturation of urine with respect to monosodium urate. J Clin. Invest. 1977,59:426.

37. Gutman Ab, Yu TF: Uric acid Nephrolithiasis. Am J Med, $1968 ; 45: 756$.

38. Bijan Shekarriz and Marshall L. Stoller: Uric acid nephrolithiasis: Current concepts and controversies. J. Urol, October 2002, 168, 1307-1314,

39. Borghi L, Meschi T., Amato F, Novarini A. Hot occupation and Nephrolithiasis. J Urol, 1993, 150:1757.

40. 40.Johnson RJ, Kivlighn SD, KIM YG: Reappraisal of the pathogenesis and consequence of cardiovascular disease and renal disease. Am J kidney Dis 1999,Feb; 33(2): 225-341.

41. 41.Baldree LA, Stapleton FB: Uric acid metabolism in children. Pediatr Clinic North, AM 1990. 
42. 42. Barrat TM,PG Duffy: Nephrocalcinosis and urolithiasis. In : Pediatric Nephrology $4^{\text {th }}$ ed wilkins; 1999; 933-46.

43 43.Band, P. R., Silverberg DS. et al. Xanthine nephropathy in a patient withlymphosarcoma treated with allupurinol. New Engl. J. med., 1970, 283: 354.

44. 44.Pak, C.Y.C., sakhaee,k and Fuller, C.; Sucessful management of uric acid nephrolithiasis with potassium citrate. Kidney Int., 1986, 30:422.

45. Resnick M.L, Kursh E.D Use of computerized tomography in the delineation of uric acid calculi. J. Urol, 1984; 131:9.

46. Nakada S.Y, Hoff, D.G, Atti S, Heisey D, Blankenbaker D. $\mathrm{M}$ : Determination of stone eomposition by noncontrast spiral computed tomography in the clinical setting. Urology.2000;55: 816 .

47. Schwart< B.F, Schenkman N, Armenakas, N.A. Imaging characteristic of indinavir calculi. J Urol 1999, 161: 1085.

48. Asplin J.R. Uric acid stones. Semin nephrol: 1996, 16:412.

49. Preminger G M. Pharmacologic treatment of uric acid calculi. Urol Clin North Am, 1987; 14;335.

50. Chughtai .M.N, Khan F.A, Kaleem M and Ahamad .M. Management of uric acid stone. JPMA 1992, 42,7:153-155.

51. Vermeulen, C. W A.: Observation on dissolution of uric acid calculi. J Urol., 1965, 94:293.

52. Sakhaee K, Hill, K, Pak C. Contrasting effect of potassium citrate and sodium citrate therapies on urinary chemistries and crystallization of stone forming salts. Kidney Int., 1983, $24 ; 348$.

53. Freed, S.Z: The alternating use of alkaizing salt and acetazolamide in the management of cystine and uric acid stones. J Urol, 1975, 113:96.
54. Low, R.K, Stoller, M.L: Uric acid related nephrolithiasis. Urol Clin North Am 1997, 24: 135.

55. Scheldon, C. A. Smith A.D.: Chemolysis of calculi. Urol. Clin. N. Amer. 1982,9:121.

56. Bernardo, N.O. Smith A D. Chemolysis of urinary calculi. Urol Clin North Am, 2000, 27: 355.

57. Breslau N.A, Brinkley L, Hill K.D. Relationship of animal protein rich diet to kidney stone formation and calcium metabolism. J Clin Endocrinol Metab.1988,66: 140.

58. Greene M.L, Fujimoto W.Y, Seegmiller J :Urinary xanthine stones- a rare complication of a llopurinol therapy. $\mathrm{N}$ Engl J.Med.1969, 280; 426.

59. Royce P.L, Fuch G.J., Lupu A.N, Chaussay C.G: The treatment of uric acid calculi with extra-corporeal shock wave lithotripsy. Br. J Urol. 1987, 60:6.

60. Teichman J.M.H, Championv P.C. Holmium: YAG lithotripsy of uric acid calculi. J. Urol,1998, 160:2130.

61. Winfield HN, Clayman RV, Chaussay CG. Monotherapy of staghorn renal calculi: Comparative study between percutaneous nephrolithotomy and extracorporeal shock wave lithotripsy. J Urol.1988; 139: 895.

62. Assismos DG, John J. Wrenn, Lloyd H. Harrison, David L. Mc Cullough, Willium H. Boyce, Carol L. Taylor et al: A comparison of anatrophic nephrolithotomy and percutaneous nephrolithotomy with and without extra-corporeal shock wave lithotripsy for management of $p$ atients $w$ ith s taghorn calculi. J Urol 1991; 145: 710. 